\title{
Integrating Replenishment Policy with GSAA-FCM Based Multi-Criteria Inventory Classification
}

\author{
Qi Zhang', Qiuhong Zhao ${ }^{1}$, Yashuai Li ${ }^{1 *}$ \\ ${ }^{1}$ School of Economics and Management, Beihang University, No. 37 of Xueyuan Road, \\ Haidian District, Beijing, 100191, China \\ E-mail: qiqfly@163.com; qhzhao@buaa.edu.cn; liyashuai@buaa.edu.cn
}

Received 21 August 2017

Accepted 25 October 2017

\begin{abstract}
It is neither practical nor economic to assign a specific inventory policy for each item if there are thousands of items in one firm. This paper seeks to solve the stock problem from an integrated perspective by taking into account of both classification of items and replenishment policies for each group. The items are first classified into different groups with respect to the similarity of predefined criteria. The fuzzy clustering-means algorithm (FCM) could help conduct the multi-criteria inventory classification, which considers annual dollar usage, lead time and criticality. Genetic algorithm and simulated annealing algorithm (GSAA) are introduced to eliminate the drawbacks (initial value sensitivity and local optimal convergence) of FCM. A modified FCM algorithm, the GSAA-FCM algorithm, is therefore proposed for classification. Based on the classification, each group is then assigned an appropriate replenishment policy through optimizing both joint replenishment period and the total costs. To demonstrate the usefulness and effectiveness of our method, an illustrative example is provided with a real dataset compared to other 9 methods in previous literature.
\end{abstract}

Keywords: Multi-criteria Inventory Classification; FCM; GSAA-FCM; Joint Replenishment Policy.

\section{Introduction}

Firms with a large number of items have been confused by how to conduct inventory strategies effectively and economically. The most comprehensively adopted inventory classification strategy is the traditional $\mathrm{ABC}$ method. Since this method only focuses on the monetary factor, many researchers doubt the reasonability of this rule. They claim that other factors, including such as lead time, criticality and commonality, should be incorporated in making classification decisions (see Refs. 1-11). Therefore, multi-criteria should be used instead of single criterion to classify inventory.
A number of different evaluation methods and models have been proposed to address multiple criteria inventory classification. An analytic hierarchy process (AHP) was introduced by Ref. 2 to categorize multiple items into different groups. Each item would get a score synthesized from the weighted criteria. Though AHP could cope with both quantitative and qualitative problems, it has always been blamed for subjective influence on pairwise comparison criteria, rating level and corresponding weight, and sorting decisions. Ref. 3 copes with the uncertainty of decision makers' preference by integrating AHP with fuzzy theory. Ref. 4 also uses a fuzzy AHP to determine weights of criteria.

\footnotetext{
* Corresponding Author.
} 
Ref. 5 develops a weighted linear optimization model, and Ref. 6 extends Ref. 5 by eliminating the opportunity for items to choose their most favorable criteria weights. Moreover, Ref. 7 points out Ref. 5 is not fit to cope large scale problem, and overcomes this problem with a simple nonlinear programming, which is extended by Ref. 8. Ref. 9 deals with the possible self-estimation problem in Refs. 5 and 6 through peer estimation. While Ref. 10 provides less subjective classification by integrating AHP with the K-means algorithm and the AHP-K-Veto method, which allow decision makers to make judgement if necessary. In addition to AHP, fuzzy theories are utilized more and more in multiple criteria inventory classification area (see Refs. 3-4, 10-12. Different from the above mentioned literature, Ref. 13 argues that classification should be done according to the characteristic of target industry and thus reference items are assigned to each group before classification.

Recently, artificial intelligence techniques have been employed to classify items. For example, Ref. 14 uses the simulated annealing algorithm (SA) to divide items into different group efficiently. Ref. 15 applies artificial neural networks (ANN) into $\mathrm{ABC}$ classification and finds that ANN performs better than multiple discriminated analysis in accuracy of prediction. The new approach provided by Ref. 16 is based on learning a weight vector by genetic algorithms (GA), while Ref. 17 applies particle swarm optimization (PSO) to solve inventory classification problem with either single objective or multi-objective. In this paper we will combine the artificial intelligence algorithms with fuzzy clustering theories to solve the multi-criteria inventory classification problem.

A very interesting phenomenon is observed through literature review and firm surveys. On the one hand, the classification theories and methods are well developed and classification is still a hot research topic. On the other hand, firms still utilize the traditional $\mathrm{ABC}$ classification for the management of multiple items. It is strange to find out that the well-developed theories are rarely adopted by firms. Classification is considered as a tool, which should serve to design more effective stock strategies. Based on the above mentioned backgrounds, this paper seeks to integrate both inventory classification and replenishment policy. As shown in Fig 1, we will first classify the large number of items (represented by small circles) into different groups (A, $\mathrm{B}, \mathrm{C})$ according to multiple criteria and then design corresponding replenishment policies $\left(\mathrm{R}_{\mathrm{A}}, \mathrm{R}_{\mathrm{B}}, \mathrm{R}_{\mathrm{C}}\right)$ for each group.

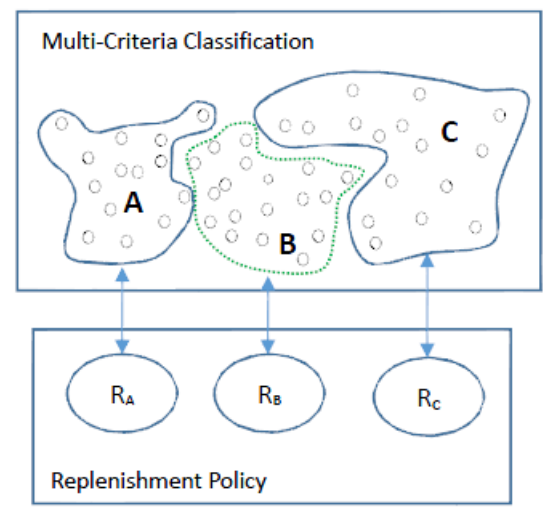

Fig. 1. The main tasks of this paper.

From firm surveys, the critical hinder preventing firms adopting the newly developed classification methods is that these methods are too complex to understand or implement. Our research thus is conducted based on the principle of easy-to-understand and simple-to-implement. In inventory classification, we choose the FCM method. However, this algorithm may converge to local optimal solution and the solution is initial value sensitive. To overcome this shortage, the GSAA-FCM method is proposed to guarantee the global optimal solution fast and effectively. All the algorithms in use are well-developed and thus firms can easily find optimization tools and software to help solve their problems. Regarding the replenishment strategy, we choose the periodic review, which is easy to conduct compared with continuous review. The optimal review period is calculated based on the classification results.

The contributions of this research lie in the follows. Firstly, this paper concurrently deals with both classification problem and replenishment strategies. Secondly, in the multi-criteria inventory classification, we integrate intelligence algorithms with the fuzzy clustering-means algorithm to get a mixed GSAA-FCM algorithm. This mixed algorithm is easy to understand and implement and could converge to the global optimal solution at a high convergence speed. Thirdly, jointreplenishment policy is applied to the items among the same group. The optimal replenishment period and the total inventory costs for each group are derived according to the classification results. Finally, the comparison with other 9 methods with the same dataset verifies the validation of our methods. Our research sheds light on how data science and computational 
intelligence can be used to serve the operations and management activities of firms.

In the remainder of the paper, Section 2 illustrates the algorithms for multi-criteria inventory classification. Joint replenishment policy is provided in Section 3. We verify the validation of the proposed model in Section 4 . Section 5 concludes the paper.

\section{Inventory Classification}

We consider a firm that owns a large number of items, and these items are different in annual usage, annual dollar usage, critical ration and lead time etc. To simplify the inventory management process, the firm should classify these items into different groups, and implement the same management policy to the items among the same group. The traditional ABC inventory classification will divide these items into three categories, A (which accounts to about $70 \%$ of the firm's capital), B (which makes about $20 \%$ of the firm's capital), and C (which takes about $10 \%$ of the firm's capital), according to a single criterion, the annual dollar usage. However, many scholars doubt the reasonability of this classification method as they argue that multiple criteria should be taken into consideration to classify the items with the most similarity into the same group (see Refs. 1-2, 6-7, 13. In our study, we integrate intelligence algorithms with the fuzzy clustering-means to solve the multi-criteria inventory classification problem.

\section{1. $F C M$}

FCM is one of the most widely used classification methods in various areas, such as computer science, large-scale data analysis, data mining, vector quantization, pattern recognition, etc (see Refs. 18-20).

Here, it is assumed that there exists a sample of $n$ items, each of which has $m$ characteristics/criteria. $X=\left[x_{i j}\right], i=1,2, \ldots, n, j=1,2, \ldots, m \quad$, represents the value of the $j$-th criterion of the $i$-th item. We will assign these items into $c$ groups/clustering centers, $V=\left\{v_{t}\right\}, t=1,2, \ldots, c$, according to the $m$ criteria. Each group contains the items with similar characteristics. The cluster results will be given by the membership matrix $U=\left[\mu_{i t}\right]$, which represents the membership score of item $i$ to group $t$. The algorithm starts with a randomly selected initial cluster centers. Then $\mu_{i t}$ can be calculated. The cluster centers and the membership degrees would get updated iteratively through the minimization of the target function $J_{c}$. This iteration procedure will stop until the position of one cluster center stops changing or the difference of target function values between two iterations is within a small enough threshold. All the above mentioned equations and parameters are listed as follows:

The objective function of FCM is given as

$$
J_{c}=\sum_{t=1}^{c} \sum_{i=1}^{n} \mu_{i t}^{b} d_{i t}{ }^{2},
$$

where $d_{i t}$ is the Euclidean distance, which represents the distance between item $i$ and clustering center $t$,

$$
d_{i t}=\left\|x_{i}-v_{t}\right\|=\sqrt{\sum_{j=1}^{m}\left(x_{i j}-v_{t j}\right)^{2}} .
$$

The membership degree is given as

$$
\mu_{i t}=1 / \sum_{r=1}^{c}\left(d_{i t} / d_{i r}\right)^{\frac{2}{b-1}},
$$

Subject to

$$
\begin{gathered}
0<\sum_{i=1}^{n} \mu_{i t}<n, \\
\sum_{t=1}^{c} \mu_{i t}=1 .
\end{gathered}
$$

Here $b(1 \leq b \leq \infty)$ is the fuzzifier, which represents the weighting exponent or fuzziness parameter, it is common to set $b=2$ (see Refs. 18 and 21).

In particular, $\mathrm{Eq}$ (4) guarantees that every group is not null. Eq (5) means that summation of a given item's membership to all groups should equal to 1 . The item will finally be assigned to the group with the highest membership value.

The cluster centers are given by 


$$
v_{t}=\sum_{i=1}^{n} \mu_{i t}^{b} x_{i} / \sum_{i=1}^{n} \mu_{i t}^{b} .
$$

Although FCM is comprehensively adopted, it has drawbacks: the results of FCM are initial value sensitive. In addition, this algorithm is essentially a local searching optimization algorithm as it may end up with local optimal convergence by using hill-climbing algorithm. To solve these problems, we integrate the genetic simulated annealing algorithm with FCM to conduct the classification.

\subsection{GSAA-FCM}

The genetic algorithm (GA) searches for the optimal solution through the evolution process (see Refs. 2223). This algorithm starts with an initial population composed by individuals (feasible solutions). It handles multiple individuals in the population simultaneously, which reduces the risk of trapping into the local optimal solution. The fitter individuals are then selected through crossover and mutation to form a new generation/population. Here fitness function $f_{i}$ is used to evaluate the fitness of individual. As FCM algorithm aims to find a solution to minimize Eq. (1), Eq. (1) will be the target of $f_{i}$, thus a smaller $J_{c}$ implies a higher fitness.

Simulated annealing algorithm (SA) is inspired by the metal annealing process (see Ref. 24). With the decline of virtual temperature, SA does not only accept the good solutions during the research process, but also accepts the inferior solutions at a certain probability. In this way, SA can jump from the trap of local optimal solution.

When incorporated with GA, SA could effectively alleviate the selection pressure of GA, and accept the new individuals from genetic operations at a probability. This would not only enhance the global convergence ability of the algorithm but also inhibit the evolution stagnation phenomenon in the late process of GA, which in turn speeds up the convergence rate. At the same time, when incorporated with SA, GA conducts the multiple searches among the solution space simultaneously, which accelerates the search speed and improves the local convergence ability of SA. In sum, the hybrid GSAA makes full use of the rapid global search ability of GA and the local search ability of SA. When integrated with FCM, the new GASS-FCM algorithm would converge fast to the global optimal solution.

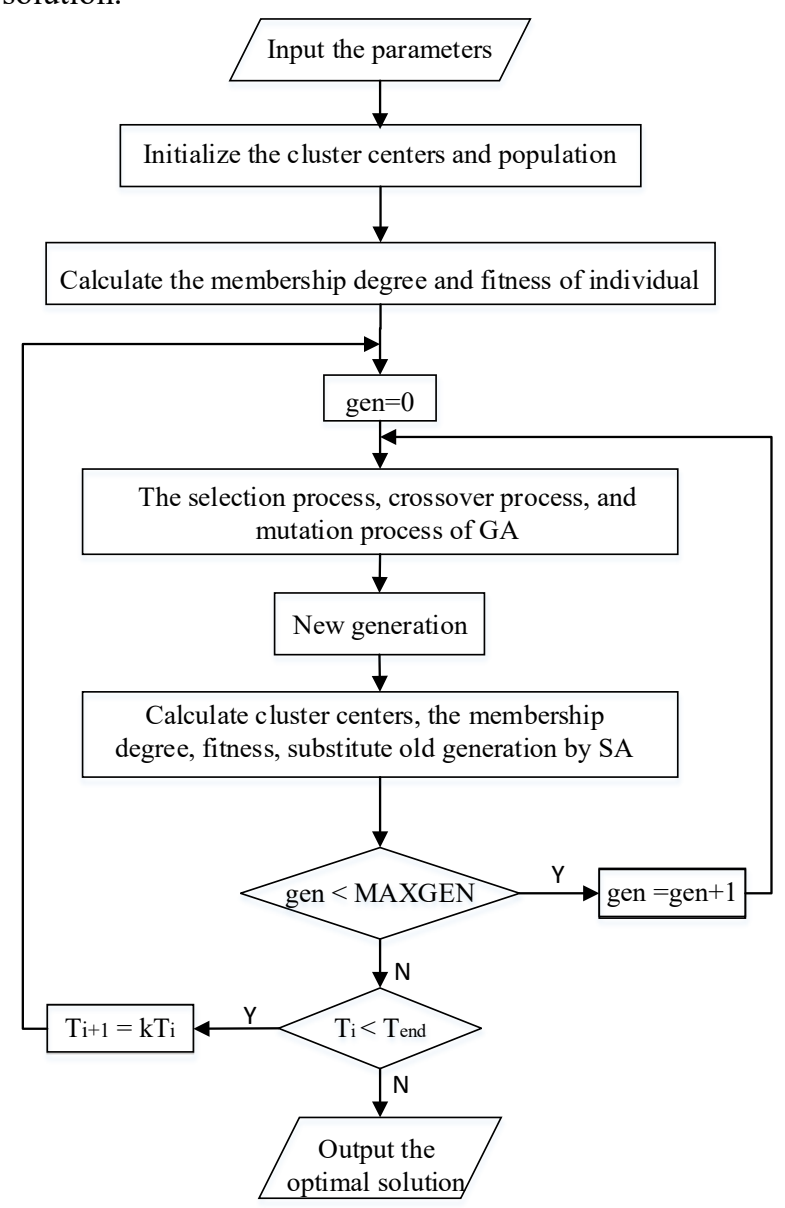

Fig. 2. The workflow of GSAA-FCM.

The workflow of GSAA-FCM is illustrated in Fig 2, and the algorithm follows the following steps:

Step 1. Predetermine the population size sizepop, the number of generations MAXGEN (the stopping criterion), the crossover probability $p_{c}$, the mutation probability $p_{m}$, the initial annealing temperature $T_{0}$, the cooling coefficient $k$, and the terminating temperature $T_{\text {end }}$.

Step 2. Initialize the cluster centers $V$, and generate the initial population Chrom, where each individual is 
represented by a chromosome. Calculate the membership degree according to Eq. (3) and derive the fitness value for each individual, $f_{i}$, where $i=1,2, \ldots$ sizepop .

Step 3. Set the loop variable of generation gen $=0$.

Step 4. Operate the selection process, crossover process and mutation process for Chrom, and calculate the cluster centers and the membership degree on the new individuals, as well as the fitness values $f_{i}^{\prime}$. If $f_{i}^{\prime}>f_{i}$, then substitute new individual for old individual; otherwise, substitute the new individual for old individual at a probability of $p=\exp \left(\left(f_{i}^{\prime}-f_{i}\right) / T\right)$.

Step 5. If gen $<M A X G E N$, then gen $=$ gen +1 , and go back to Step4, otherwise, go to Step 6.

Step 6. If $T_{i}<T_{\text {end }}$, the algorithm ends with the global optimal solution; otherwise, set $T_{i=1}=k T_{i}$, and go back to Step 3.

\section{Replenishment Policy}

If firms are in charge of a large number of items, they want to find an efficient method to manage these items. Generally, there are two types of replenishment policy, one is continuous review, and the other is periodic review. It is costly and unpractical to monitor the stock condition of each item continuously if the firm keeps thousands of items. In this regard, we try to explore a simpler and easier to conduct method, periodic review. By which, the items in the same group will be reviewed and replenished in the same interval. Thus, firms have to decide the joint replenishment period for each group in order to minimize the inventory costs.

The GSAA-FCM would give the classification results of items. We use the binary variable $x_{i t}$ to indicate whether item $i$ belongs to group $t$. If $x_{i t}=1$, it means $i$ belongs to group $t$, and $i$ does not belong to group $t$ if $x_{i t}=0$. It is a common practice in inventory management to consider only the setup cost and the holding cost (see Refs. 14 and 26). Thus we will derive the replenishment period for each group by minimizing the sum of setup costs and holding costs. The annual cost for items in group $t$ is given as

$$
\min _{R_{t}} \sum_{i=1}^{n}\left(\frac{s_{i}}{R_{t}}+\frac{D_{i} h_{i} R_{t}}{2}\right) x_{i t} .
$$

Here, for item $i, s_{i}$ is the unit setup cost, $D_{i}$ is the demand rate, $h_{i}$ is the holding cost per unit per time, while $R_{t}$ is the replenishment period for items in group $t$. The first part in the brackets in Eq. (7) is the setup cost for item $i$, and the second part is the holding cost for item $i$.

The optimal solution is

$$
R_{t}^{*}=\sqrt{2 \sum_{i=1}^{n} s_{i} x_{i t} / \sum_{i=1}^{n} D_{i} h_{i} x_{i t}} .
$$

The total annual costs for all the items is given by

$$
\sum_{t=1}^{c} \sum_{i=1}^{n}\left(s_{i} / R_{t}^{*}+D_{i} h_{i} R_{t}^{*} / 2\right) x_{i t} .
$$

\section{The Application of Proposed Methods}

Inventory classification is critical to simplify the stock management and reduce costs. Nevertheless, few illustrates in detail how their methods achieve this goal. In this section, we will show how our new method outperforms the existing methods in cost-saving validity.

\subsection{Data resource and cost parameter assumptions}

For comparison convenience, we apply our method to the dataset provided by Ref. 27, for the same dataset has been used by 9 existing methods proposed by Refs. 2, 510 and 14. There are 47 items in this dataset, we use annual dollar usage, lead time, and the critical factor as the criteria to distribute the items into three groups through GSAA-FCM, and then calculate the replenishment period as well as the total costs by Eqs. (8) and (9). We also calculate the total costs under periodic review policy for the given classification solutions by the other 9 methods.

Dividing the annual dollar usage by the average unit cost, we get the demand rate $D_{i}$. It is commonly assumed that holding cost is about $20 \%$ of the item's average unit cost (see Ref. 26), and the setup cost is positive related to the lead time (see Ref. 14). In this way, we set $s_{i}^{\prime}$ as the coefficient of setup cost and $h_{i}^{\prime}$ as the coefficient of holding cost for item $i$. In this way, the setup cost (holding cost) is the product of the coefficient and the lead time (the average unit cost). 
Generally speaking, replenishment policy is a tradeoff between holding cost and setup cost ( $h_{i}$ vs $s_{i}$ ): When the holding cost is higher than the setup cost, it will be optimal to shorten the replenishment period in order to reduce holding cost. Oppositely, if holding cost is relatively lower than setup cost, it will be reasonable to extend the replenishment period in order to reduce replenishment times and setup cost. To guarantee the robustness of the numerical results, we vary $s_{i}^{\prime}$ to get different costs structures.

\subsection{Comparison of our method with existing methods}

We summarize the classification solutions of our new method and the other existing 9 methods in Table 1. It shows that (1) the group has the least replenishment period is labeled as Class A in our model; (2) the group with the largest replenishment period is labeled as Class $\mathrm{C}$ while the third group is labeled as Class B. For space limitation, we put Table 1 in Appendix A.

Table 1 shows that only 8 of the 47 items have the common classification by these 10 methods. This implies that these 10 methods distinguish from one another someway. Particularly, we notice the classification results of Ref. 5 and our new model show less similarity with the solutions of other methods. Whereas, we also observe there are some similarity in classification among different methods. For instance, there are 43 items have the same group-attribution by the two method proposed by Ref. 10. 45 among the total 47 items are attributed to the same class by Ref. 7 and Ref. 8, and 42 among 47 items are assigned to the same group by Refs. 7 and 6; while 41 among the total 47 item are same classified by Refs. 6 and 8; 40 items are identically attributed by Refs. 7 and 9, in sum, Refs. 6-9 show obvious similarity in classification.

We vary $s_{i}^{\prime}$ from 0.05 to 0.2 , and then to 0.5 , while keep $h_{i}^{\prime}$ fixed at 0.2 , to see the total costs under different methods. As can be seen from Table 1, our method dominates all the other methods and leads to the smallest total annual cost. This conclusion verifies the efficiency of our method. Our method could lead to the lowest total cost under different costs structures. This implies that our method is applicable in real cases.

\section{Conclusion and Discussion}

In order to manage a large number of items in stock, we study classification problem from an integrated perspective by combining inventory classification with stock policy. In this paper, FCM is combined with artificial intelligence algorithms (GA and SA). These three algorithms could mutually complement each other and turn into an efficient GSAA-FCM algorithm, which converges fast to globally optimal solution. Compared with other 9 existing classification solutions, our solution leads to the lowest inventory costs. This implies that our study is with vital application value. In addition, our study also reveals that handling complex data with well-designed intelligent algorithm will benefit firms.

\section{Acknowledgements}

This work is supported by National Natural Science Foundation of China (Grant Number 71471006 and 71502008).

\section{References}

1. M. Cohen and Ft. Ernst, Multi-item classification and generic inventory stock control policies, Production and Inventory Management Journal 29 (3) (1988) 6-8.

2. B. E. Flores, D. L. Olson and V. K. Dorai, Management of multicriteria inventory classification, Mathematical and Computer Modeling 16 (12) (1992) 71-82.

3. O. Cakir and M. S. Canbolat, A web-based decision support system for multi-criteria inventory classification using fuzzy AHP methodology, Expert Syst. Appl. 35(3) (2008) 1367-1378.

4. A. Hadi-Vencheh and A. Mohamadghasemi, A fuzzy AHP-DEA approach for multiple criteria ABC inventory classification, Expert Syst. Appl. 38 (2011) 3346-3352.

5. R. Ramanathan, $\mathrm{ABC}$ inventory classification with multiple-criteria using weighted linear optimization, Comput. Oper. Res. 33(3) (2006) 695700 .

6. P. Zhou and L. Fan, A note on multi-criteria ABC inventory classification using weighted linear optimization, Eur. J. Oper. Res. 182 (3) (2007) 14881491.

7. W. L. Ng, A simple classifier for multiple criteria ABC analysis, Eur. J. Oper. Res. 177 (2007) 344353. 
8. A. Hadi-Vencheh, An improvement to multiple criteria $\mathrm{ABC}$ inventory Classification, Eur. J. Oper. Res. 201(3) (2010) 962-965.

9. J. X. Chen, Peer-estimation for multiple criteria ABC inventory classification, Comput. Oper. Res. 38(12) (2011) 1784-1791.

10. F. Lolli, A. Ishizaka and R. Gamberini, New AHPbased approaches for multi-criteria inventory classification, Int. J. Production Economics 156 (2014) 62-74.

11. B. Soylu and B. Akyol, Multi-criteria inventory classification with reference items, Comput. Ind. Eng. 69 (2014) 12-20.

12. S. Perçin and C. Kahraman, An integrated fuzzy multi-criteria decision-making approach for six sigma project selection, Int. J. Comput Intelligence Syst. 3(5) (2010) 610-621.

13. G. A. Keskin and C. Özkan, Multiple criteria ABC analysis with FCM clustering, Journal of Indusrtrial Engineering (2013) 1-7.

14. D. Mohammaditaba, S. H. Ghodsypour and C. O'Brien, Inventory control system design by integrating inventory classification and policy selection, Int. J. Production Economics 140 (2012) 655-659.

15. F.Y. Partovi and M. Anandarajan, Classifying inventory using an artificial neural network approach, Comput. Ind. Eng. 41(4) (2002)389-404.

16. H. A. Güvenir and E. Erel, Multicriteria inventory classification using a genetic algorithm, Eur. J. Oper. Res. 105 (1998)29-37.

17. C. Y. Tsai and S. W.Yeh, A multiple objective particle swarm optimization approach for inventory classification, Int. J. Production Economics 114 (2008) 656-666.
18. K. Zhou, and S. Yang, Exploring the uniform effect of FCM clustering: A data distribution perspective, Knowledge-Based Systems 96 (2016) 76-83.

19. K. S. Chuang, H. L. Tzeng, S. Chen, J. Wu and T. J. Chen, Fuzzy c-means clustering with spatial in formation for image segmentation, Comput. Med. Imaging Graph.30 (2006) 9-15.

20. H. Izakian and A. Abraham, Fuzzy C-means and fuzzy swarm for fuzzy clustering problem, Expert Syst. Appl. 38 (2011)1835-1838.

21. N. R. Pal and J. C. Bezdek, On cluster validity for the fuzzy c-means model, IEEE Trans. Fuzzy Syst. 3 (1995) 370-379.

22. R. L. Haupt and S. E. Haupt, Practical genetic algorithms. (John Wiley \& Sons, New York 1998).

23. Z. Michalewicz, Genetic algorithms + data structures $=$ evolution programs (2nd). (SpringerVerlag, New York, 1994).

24. G. Demiroz and C. Yilmaz, Using simulated annealing for computing cost-aware covering arrays, Applied Soft Computing 49 (2016) 11291144.

25. Y. R. Zeng, L. P. Peng, J. Zhang and L. Wang, An effective hybrid differential evolution algorithm incorporating simulated annealing for joint replenishment and delivery problem with trade credit, Int. J. Comput. Intelligence Syst. 9(6) (2016) 1001-1015.

26. S. Chopra and P. Meindl, Supply chain management: strategy, planning and operation (5th edition). (Pearson, New Jersey, 2012).

27. R. Reid, The ABC method in hospital inventory management: a practical approach, Prod. Invent. Manag. 28 (4) (1987) 67-70.

\section{Appendix A.}

Table 1. Comparison of the classification by different methods and our new model.

\begin{tabular}{|c|c|c|c|c|c|c|c|c|c|c|}
\hline Item no. & [2] & [5] & [7] & [6] & [8] & [9] & [13] & $\begin{array}{l}{[10] \mathrm{A}} \\
\mathrm{HP}-\mathrm{K} \\
\end{array}$ & $\begin{array}{l}{[10] \mathrm{AHP}} \\
\text {-K-Velto }\end{array}$ & $\begin{array}{l}\text { New } \\
\text { model }\end{array}$ \\
\hline 1 & $\mathrm{~A}$ & $\mathrm{~B}$ & $\mathrm{~A}$ & $\mathrm{~A}$ & $\mathrm{~A}$ & $\mathrm{~A}$ & $\mathrm{~A}$ & $\mathrm{~B}$ & $\mathrm{~B}$ & $\mathrm{~A}$ \\
\hline 2 & A & $\mathrm{C}$ & A & A & A & A & A & A & A & A \\
\hline 3 & A & $\mathrm{C}$ & $\mathrm{A}$ & A & A & A & A & A & B & A \\
\hline 4 & $\mathrm{C}$ & $\mathrm{A}$ & $\mathrm{A}$ & $\mathrm{C}$ & A & B & A & $\mathrm{C}$ & B & $\mathrm{A}$ \\
\hline 5 & B & $\mathrm{C}$ & $\mathrm{A}$ & B & A & B & A & B & B & B \\
\hline 6 & $\mathrm{C}$ & $\mathrm{C}$ & $\mathrm{A}$ & $\mathrm{C}$ & B & B & A & B & B & $\mathrm{C}$ \\
\hline 7 & $\mathrm{C}$ & $\mathrm{C}$ & B & $\mathrm{C}$ & B & B & A & B & B & B \\
\hline 8 & $\mathrm{C}$ & $\mathrm{C}$ & B & B & B & B & A & $\mathrm{C}$ & $\mathrm{C}$ & B \\
\hline 9 & A & $\mathrm{C}$ & $\mathrm{A}$ & $\mathrm{A}$ & A & A & A & A & B & B \\
\hline 10 & B & $\mathrm{C}$ & $\mathrm{A}$ & A & A & A & A & B & B & B \\
\hline 11 & B & $\mathrm{C}$ & $\mathrm{C}$ & $\mathrm{C}$ & $\mathrm{C}$ & $\mathrm{C}$ & A & B & B & $\mathrm{C}$ \\
\hline 12 & $\mathrm{~B}$ & $\mathrm{C}$ & $\mathrm{B}$ & B & $\mathrm{B}$ & $\mathrm{B}$ & $\mathrm{B}$ & $\mathrm{B}$ & $\mathrm{B}$ & $\mathrm{C}$ \\
\hline
\end{tabular}


Table 1. Comparison of the classification by different methods and our new model. (Cont'd)

\begin{tabular}{|c|c|c|c|c|c|c|c|c|c|c|}
\hline Item no. & {$[2]$} & [5] & [7] & [6] & {$[8]$} & [9] & [13] & $\begin{array}{l}{[10] \mathrm{A}} \\
\mathrm{HP}-\mathrm{K}\end{array}$ & $\begin{array}{l}{[10] A H P} \\
\text {-K-Velto }\end{array}$ & $\begin{array}{l}\text { New } \\
\text { model }\end{array}$ \\
\hline 13 & $\mathrm{~A}$ & $\mathrm{C}$ & $\mathrm{A}$ & $\mathrm{A}$ & $\mathrm{A}$ & $\mathrm{A}$ & $\mathrm{B}$ & $\mathrm{A}$ & B & $\mathrm{C}$ \\
\hline 14 & B & A & B & B & A & B & B & B & B & $\mathrm{C}$ \\
\hline 15 & A & A & $\mathrm{C}$ & $\mathrm{C}$ & $\mathrm{C}$ & C & B & B & B & $\mathrm{C}$ \\
\hline 16 & $\mathrm{C}$ & A & $\mathrm{C}$ & $\mathrm{C}$ & $\mathrm{C}$ & C & B & B & B & C \\
\hline 17 & B & B & $\mathrm{C}$ & $\mathrm{C}$ & $\mathrm{C}$ & $\mathrm{C}$ & B & B & B & $\mathrm{C}$ \\
\hline 18 & A & A & B & B & B & B & B & B & B & $\mathrm{C}$ \\
\hline 19 & B & A & B & B & B & B & B & B & B & $\mathrm{C}$ \\
\hline 20 & B & B & $\mathrm{C}$ & $\mathrm{C}$ & $\mathrm{C}$ & $\mathrm{C}$ & B & B & B & $\mathrm{C}$ \\
\hline 21 & A & B & $\mathrm{C}$ & $\mathrm{C}$ & $\mathrm{C}$ & C & B & B & B & $\mathrm{C}$ \\
\hline 22 & B & B & $\mathrm{C}$ & $\mathrm{C}$ & $\mathrm{C}$ & $\mathrm{C}$ & B & B & B & $\mathrm{C}$ \\
\hline 23 & A & B & B & B & B & $\mathrm{C}$ & B & A & B & C \\
\hline 24 & A & $\mathrm{C}$ & $\mathrm{C}$ & $\mathrm{C}$ & $\mathrm{C}$ & $\mathrm{C}$ & B & B & B & $\mathrm{C}$ \\
\hline 25 & C & C & C & C & $\mathrm{C}$ & C & C & C & C & C \\
\hline 26 & $\mathrm{C}$ & $\mathrm{C}$ & $\mathrm{C}$ & $\mathrm{C}$ & $\mathrm{C}$ & $\mathrm{C}$ & $\mathrm{C}$ & C & $\mathrm{C}$ & $\mathrm{C}$ \\
\hline 27 & $\mathrm{C}$ & B & $\mathrm{C}$ & $\mathrm{C}$ & $\mathrm{C}$ & $\mathrm{C}$ & $\mathrm{C}$ & $\mathrm{C}$ & $\mathrm{C}$ & $\mathrm{C}$ \\
\hline 28 & C & A & B & B & B & A & $\mathrm{C}$ & B & B & C \\
\hline 29 & B & A & A & A & A & A & $\mathrm{C}$ & B & B & $\mathrm{C}$ \\
\hline 30 & C & C & C & C & $\mathrm{C}$ & C & C & C & C & C \\
\hline 31 & B & B & B & B & B & B & B & B & B & $\mathrm{C}$ \\
\hline 32 & B & $\mathrm{C}$ & $\mathrm{C}$ & $\mathrm{C}$ & $\mathrm{C}$ & $\mathrm{C}$ & B & B & B & $\mathrm{C}$ \\
\hline 33 & C & B & B & B & B & B & $\mathrm{C}$ & C & $\mathrm{C}$ & C \\
\hline 34 & $\mathrm{C}$ & A & B & B & B & A & $\mathrm{C}$ & B & B & $\mathrm{C}$ \\
\hline 35 & C & C & C & C & $\mathrm{C}$ & C & $\mathrm{C}$ & $\mathrm{C}$ & C & C \\
\hline 36 & B & $\mathrm{C}$ & $\mathrm{C}$ & $\mathrm{C}$ & $\mathrm{C}$ & $\mathrm{C}$ & B & B & B & $\mathrm{C}$ \\
\hline 37 & $\mathrm{C}$ & B & $\mathrm{C}$ & B & $\mathrm{C}$ & B & $\mathrm{C}$ & $\mathrm{C}$ & $\mathrm{C}$ & $\mathrm{C}$ \\
\hline 38 & C & C & C & $\mathrm{C}$ & C & C & B & B & B & $\mathrm{C}$ \\
\hline 39 & $\mathrm{C}$ & B & B & B & B & B & $\mathrm{C}$ & $\mathrm{C}$ & $\mathrm{C}$ & $\mathrm{C}$ \\
\hline 40 & C & B & B & B & B & B & $\mathrm{C}$ & B & B & C \\
\hline 41 & $\mathrm{C}$ & $\mathrm{C}$ & $\mathrm{C}$ & $\mathrm{C}$ & $\mathrm{C}$ & $\mathrm{C}$ & $\mathrm{C}$ & $\mathrm{C}$ & $\mathrm{C}$ & $\mathrm{C}$ \\
\hline 42 & $\mathrm{C}$ & $\mathrm{C}$ & $\mathrm{C}$ & $\mathrm{C}$ & $\mathrm{C}$ & $\mathrm{C}$ & $\mathrm{C}$ & $\mathrm{C}$ & $\mathrm{C}$ & $\mathrm{C}$ \\
\hline 43 & $\mathrm{C}$ & B & $\mathrm{C}$ & $\mathrm{C}$ & $\mathrm{C}$ & $\mathrm{C}$ & $\mathrm{C}$ & $\mathrm{C}$ & $\mathrm{C}$ & $\mathrm{C}$ \\
\hline 44 & $\mathrm{C}$ & $\mathrm{C}$ & $\mathrm{C}$ & $\mathrm{C}$ & $\mathrm{C}$ & $\mathrm{C}$ & $\mathrm{C}$ & $\mathrm{C}$ & $\mathrm{C}$ & $\mathrm{C}$ \\
\hline 45 & B & A & B & B & B & A & $\mathrm{C}$ & B & B & C \\
\hline 46 & $\mathrm{C}$ & $\mathrm{C}$ & $\mathrm{C}$ & $\mathrm{C}$ & $\mathrm{C}$ & $\mathrm{C}$ & $\mathrm{C}$ & $\mathrm{C}$ & $\mathrm{C}$ & $\mathrm{C}$ \\
\hline 47 & C & B & $\mathrm{C}$ & C & $\mathrm{C}$ & C & C & $\mathrm{C}$ & $\mathrm{C}$ & $\mathrm{C}$ \\
\hline \multicolumn{11}{|l|}{ Total costs } \\
\hline $\mathrm{S}_{\mathrm{i}}=0.05, \mathrm{~h}_{\mathrm{i}}=0.2$ & 1460.2 & 461.8 & 470.1 & 487.9 & 479.3 & 484.8 & 433.8 & 469.3 & 422.3 & 389.7 \\
\hline $\mathrm{S}_{\mathrm{i}}=0.2, \mathrm{~h}_{\mathrm{i}}=0.2$ & 963.6 & 923.5 & 940.2 & 975.8 & 958.5 & 969.6 & 867.6 & 938.6 & 844.6 & 779.4 \\
\hline $\mathrm{S}_{\mathrm{i}}=0.5, \mathrm{~h}_{\mathrm{i}}=0.2$ & 1523.6 & 1460.2 & 1486.5 & 1542.9 & 1515.6 & 1533.1 & 1371.7 & 1484.0 & 1335.5 & 1232.3 \\
\hline
\end{tabular}

